\title{
NI DOBLAJE NI SUBTITULACIÓN. EL GRAN ÉXITO DEL VOICE-OVER EN LA TELEVISIÓN POLAGA
}

\author{
Katarzyna Górska \\ Universitat Pompeu Fabra
}

\section{INTRODUCCIÓN}

En comparación con la subtitulación y el doblaje, el voice-over es con toda probabilidad la modalidad de la traducción audiovisual que menos interés ha suscitado en el ámbito académico (Franco et al. 2010). En muchos países se utiliza solo en traducciones de documentales o noticias, pero en otros, como en Polonia, el voice-over es empleado también en la traducción de obras de ficción. En el conjunto de la Unión Europea, y pese a las manifestaciones de algunos autores, como Chaume (2012), que de forma genérica mantienen que el voice-over sigue presente en los antiguos países bajo la órbita soviética, lo cierto es que solo cinco estados miembros de la Unión Europea mantienen viva dicha modalidad: además de la citada Polonia, Lituania, Letonia, Bulgaria y, aunque de forma parcial Estonia (Comisión Europea 2011). A los que cabe añadir, aunque fuera ya del ámbito de la Unión Europea, Rusia y Ucrania.

La realidad del voice-over ha sido tradicionalmente analizada desde un plano normativo y con un sesgado marco empírico de referencia. Ello ha dado como resultado un conjunto de conclusiones y lugares comunes un tanto simplistas, por reduccionistas, y cuyo escepticismo o incluso valoración negativa respecto al voice-over no suele hacer honor a la verdad. La práctica cotidiana se sitúa, sin embargo, al margen de esas discusiones y en Polonia el voice-over constituye la modalidad de traducción audiovisual más frecuente y también la preferida por los espectadores.

El presente trabajo retoma este controvertido objeto y aborda algunas de las razones por las que el voice-over sigue triunfando actualmente en la televisión polaca. Asimismo, en un esfuerzo por contextualizar esa práctica en un marco de análisis más amplio, esta contribución presenta también el voice-over en comparación con la subtitulación y el doblaje proponiendo así un esquema comparativo entre esas tres modalidades de traducción audiovisual.

De acuerdo con todo lo anterior, esta contribución se estructura de la siguiente manera. Tras esta introducción se presenta un breve epígrafe que contextualiza la mala reputación de esta modalidad de traducción audiovisual al que siguen los dos epígrafes que con- 
forman el núcleo de la contribución. El primero de ellos aborda la definición y la naturaleza del voice-over, mientras que el segundo revisa las causas explicativas de la persistencia del voice-over en la traducción de las obras de ficción en la televisión polaca.

\section{LA MALA FAMA DEL VOICE-OVER}

Por una u otra razón el voice-over siempre ha gozado de mala fama. Ejemplo de ello es el artículo publicado en The New York Times a principio de la década de los noventa, titulado Why Marilyn Monroe is a Polish Baritone (Glaser 1991), en el que se ironiza sobre esta práctica arguyendo que: «Joan Collins's acrid put-downs on Dynasty are thus heard by Poles as a local baritone. Marilyn Monroe's breathy come-ons in Some Like It Hot are heard as a deep monotone, and Jane Fonda's seductive voice in Barbarella emerges as flat drone». Los profesionales y los investigadores en el campo de la traducción audiovisual tampoco se han pronunciado de manera más entusiasta, llegando a considerar el voice-over como «tremendamente tedioso y monótono» (Barzdevics 2012: 62). Esta opinión puede observarse incluso entre algunos de los autores polacos que han tratado el tema, que coinciden en el menosprecio por esta modalidad. En esta línea Pisarska y Tomaszkiewicz consideran que (1996: 192):

En Polonia existen tres técnicas de traducción de películas: lista de diálogos leída por un lector (presente sobre todo en la televisión), el doblaje y la traducción en forma de los subtítulos. Dejaremos de lado la primera de esas técnicas, ya que por razones de estética y calidad en la recepción de una película por parte de los espectadores, esa voz monótona del lector, que se solapa con las voces originales, seguramente no ayuda a la recepción de todo lo que se transmite en la película. Además, es una técnica desconocida en el Occidente. Ocupémonos pues del doblaje y de la subtitulación'1. (trad. KG).

Pero a pesar de esas opiniones, el voice-over sigue estando muy presente en la televisión polaca y nada augura su desaparición ni en el corto ni en el medio plazo. Así pues, en vez de silenciar su existencia parece más sensato preguntarse por los motivos de su persistencia y éxito relativo, objetivos sobre los que versarán los siguientes epígrafes.

\section{LA DEFINICIÓN Y LA NATURALEZA DEL VOICE-OVER}

A efectos estrictamente desambiguadores, cabe decir en primer lugar que el voice-over no debe ser confundido con el voice-off. Mientras que este último se refiere a la situación en la que, por conveniencia del guion, se puede oír la voz de un personaje del film que se encuentra fuera de plano, el voice-over se refiere a la modalidad de traducción audiovisual en la que a la pista de audio original se superpone una voz que no pertenece a la obra, y que lee la traducción de los diálogos originales. Es por ello que el voice-over ha sido considerado como una «disembodied voice» (Doane 1985: 168), ya que precisamente esa voz superpuesta no pertenece a ninguno de los personajes de la película.

Las raíces del voice-over hay que buscarlas en la desaparecida URSS, en la llamada «traducción Gavrilov» (Franco et al. 2010), que consistía en la interpretación de películas extranjeras

1 Todas las citas literales de esta contribución con un texto original en la lengua polaca han sido traducidas por su propia autora. En esos casos se hará notar con la expresión «(trad. KG)».

Quaderns, 10 (2015), pp. 63-72 
para los comités estatales de cinematografía o incluso para festivales de cine. Al principio esas interpretaciones se realizaban en vivo, pero con la aparición de la tecnología de reproducción de vídeo VHS empezaron a ser grabadas. El nombre proviene de Andrey Gavrilov, uno de los intérpretes más famosos de esa época, que acabó dando nombre a esa modalidad.

En el caso de Polonia, los orígenes del voice-over, sin embargo, no resultan tan claros. Algunos trabajos, como el de Bogucki (2004), tratan el voice-over como un claro legado soviético, mientras que otros mantienen que esa modalidad fue originada en los noticiarios de cine, parecidos al NO-DO en España (Garcarz 2007). Sea como fuere, el público polaco se acostumbró tanto a esas descripciones y comentarios superpuestos a la imagen y audio que, años más tarde, esa práctica fue aceptada con toda naturalidad para la televisión.

Por otro lado, como sucede también con otros muchos fenómenos del campo de los estudios en traducción, no existe todavía un consenso terminológico para referirse al fenómeno del voice-over. Así, por ejemplo, Glaser (1991) emplea el término reading, mientras que en polaco se suele emplear la expresión versión del lector (Hendrykowski 1984), enfatizando de esta manera que la propia naturaleza del voice-over radica precisamente en la lectura de las traducciones ad hoc de los diálogos de las obras, cuya grabación acaba quedando superpuesta a la pista de audio original. Garcarz (2007) señala, además, que entre los profesionales polacos dedicados a leer esas traducciones, en adelante los «lectores», esta modalidad suele llamarse «susurrado», término que también denota la «interpretación simultánea que se efectúa en voz baja al oído del destinatario» (Hurtado Albir 2013: 70). Algunos autores, como Barzdevics (2012), proponen el término «voz superpuesta», que podría considerarse una buena alternativa en lengua española. En el presente trabajo, no obstante, se ha optado por utilizar el vocablo inglés voice-over, para no dilatar este debate terminológico.

Como ya se dijo, la característica principal del voice-over es la superposición de una voz a la pista audio de la obra original, que lee el texto de la traducción por encima de las voces de los actores de la película. Por ello no se da, como en el doblaje, sincronía labial, lo que en muchas ocasiones evita la introducción de cambios en la traducción solo para que las palabras «encajen» en la boca de los personajes. En cambio el voice-over sí permite la «kinetic/action synchrony» (Franco et al. 2010: 43) y, sobre todo, la isocronía. Aunque la voz del «lector» entre un par de segundos más tarde que el parlamento original, suele tener la misma duración o incluso acabarse antes para permitir al espectador disfrutar de las voces originales, aunque sea por un mínimo lapso de tiempo. En cambio, en lo que refiere al tipo vocal idiosincrásico (Barzdevics 2012), este no es siempre tenido en cuenta en las versiones voice-over, lo que muchas veces ha sido utilizado como uno de los argumentos en contra de esta modalidad, como ejemplifica el provocativo título del artículo de Glaser (1991).

A pesar de compartir muchos rasgos en común, la evidencia demuestra que la práctica del voice-over presenta distintas particularidades en los países que lo han adoptado. Woźniak (2008) subraya en este sentido, por ejemplo, que en Rusia y Ucrania suele recurrirse al llamado "doblaje ruso», en el que los enunciados de un personaje femenino siempre son leídos e interpretados por un «lector» mujer, mientras que los de un personaje masculino lo son por un «lector» varón. En Polonia, en cambio, todo el texto es leído por un único «lector», que en las obras de ficción suele ser un varón ${ }^{2}$ y que evita a toda costa interpretar el texto, limitándose más bien a «proporcionarlo».

2 En el caso de las obras de no-ficción ese sesgo es mucho menor (Szarkowska 2009). 
Es importante señalar, como ya se iba reiterando anteriormente, que el voice-over comparte algunas de sus características con otras modalidades de la traducción audiovisual, tales como subtitulación y doblaje. Antes que nada, sin embargo, no puede omitirse la compleja naturaleza comunicativa de las obras audiovisuales, en la que participan y se superponen varios códigos. En este sentido, Zabalbeascoa (2001: 113) afirma que: «el típico texto audiovisual se caracteriza por la presencia simultánea y combinada de dos códigos de signos, el verbal y el no verbal, y dos canales de comunicación, el acústico y el óptico (audio y visual, desde la perspectiva perceptiva)». Y ello es esencial para la contextualización de la traducción audiovisual, pues ésta queda subordinada (Hurtado Albir 2013) a una pluralidad de canales y códigos, no solo el lingüístico. Por ello parece imposible que la traducción audiovisual «oculte» su condición de traducción, ya que todas y cada una de sus modalidades acabarán afectando de algún modo a uno de los aspectos de la obra, bien sea la imagen en lo que refiere a la subtitulación, bien sea el audio en el caso del doblaje, pudiéndose considerar el voice-over como una modalidad a medio camino entre las anteriores.

Como subraya Garcarz (2007) de manera general, el voice-over no es tan visible en la obra como los subtítulos, que inevitablemente siempre traen a la mente que se trata de una traducción. Además, no se le identifica tanto con el texto de llegada como las voces de los actores en el doblaje. Podría decirse que el voice-over no se «apropia» con tanta rotundidad de la obra como sucede en el caso del doblaje, toda vez que permite de algún modo evitar «el contraste cultural» al que se refieren Pisarska y Tomaszkiewicz (1996: 196):

no hay duda de que uno de los elementos fundamentales de esa realidad [de una película] es el idioma de los personajes de la obra. Un vaquero que habla en polaco, un samurái que habla en inglés o el dueño de una pizzería en Roma que habla en alemán, supone un fuerte contraste cultural que de antemano crea una distancia entre el espectador y la película. El espectador sabe y siente, que toda esa situación es "engañosa" (trad. KG).

Hechas esas salvedades y contraponiendo el doblaje y el voice-over, lo primero que cabe decir es que ambas modalidades comparten el canal de transmisión acústico. La diferencia radica, no obstante, en que en el voice-over la pista original sigue estando presente en todo momento, aunque en un volumen más bajo, lo que permite oír de manera superpuesta la voz del «lector» y supone una garantía de que el texto no haya sido excesivamente manipulado (Woźniak 2008). Otra diferencia es la falta de interpretación del texto traducido por parte de los «lectores» polacos, lo que sí constituye una característica intrínseca del doblaje. Ese matiz queda recogido en la opinión de algunos «lectores», como Stanisław Olejniczak (Jeczeń 2006), que considera que la tarea de un buen «lector» se constata cuando los espectadores ni tan siquiera se percatan de su lectura, porque de hecho lo que debería despertar las emociones del público es la película, no el «lector». Como es lógico, tampoco intentan imitar acentos con los que hablan los personajes y todo el texto se pronuncia en un polaco estándar. «Es como contar a los espectadores un cuento» resume Maciej Gudowski, otro de los «lectores» polacos más populares (Jeczeń 2006).

Por otro lado, el voice-over comparte algunas características también con la subtitulación, la modalidad preferida por muchos autores, como Hendrykowski (1982: 141), quien sostiene que «los subtítulos siguen siendo el mal menor necesario, sobre todo en el caso de 
obras maestras, ya que evitan la mutilación de su valor artístico» (trad. KG). Si se contrapone el voice-over y la subtitulación cabe decir en primer lugar que ambas modalidades comparten la presencia de la pista audio de la obra original. En ese sentido, en los dos casos se permite al espectador disfrutar de las voces de los actores que aparecen en la película, ya que la voz, al fin y al cabo, no deja de ser una de las principales herramientas de expresión. En este sentido, al igual que la subtitulación, ello permite considerar el voice-over una traducción vulnerable (Espasa 2004), ya que en ambos casos la traducción puede ser, de alguna manera, cotejada con el texto original.

Otro aspecto compartido por estas dos modalidades de traducción audiovisual son algunas de las técnicas utilizadas, puesto que el voice-over suele recurrir a la eliminación y condensación del texto con el fin de que el texto leído por el «lector» encaje temporalmente con los enunciados de los personajes en pantalla. Entre los elementos que suelen ser eliminados se cuentan, entre otros, los nombres propios, las palabras extranjeras que suenan igual en ambas lenguas o las repeticiones de carácter expresivo, aunque se calcula que esas pérdidas no llegan a ser tan graves como en el caso de la subtitulación (Tomaszkiewicz 2006).

Probablemente la diferencia más grande entre el voice-over y la subtitulación es la ausencia de cambio de canal semiótico. El código acústico, que transmite signos verbales, según el esquema de Delabastita (1989), se mantiene, y evita que se produzca un cambio al canal visual, como en el caso de la subtitulación. Ello permite el pleno disfrute de la imagen del film, ya que no requiere que la atención del espectador se divida entre la imagen y la subtitulación. En palabras de Woźniak (2008: 77):

Aunque muchos procesos de reducción del texto en la subtitulación se basan en la premisa de que el espectador será capaz de reconstruir el contenido eliminado gracias a los elementos visuales del texto y la pista audio original, se puede contar con ello solo hasta cierto punto, ya que tener que bajar la vista, concentrarse en leer los subtítulos y volver a subir la vista, disminuye en gran medida la calidad de la percepción de la imagen y el audio del original. (trad. KG)

El mantenimiento del canal de transmisión permite evitar también el rigor que requiere la lengua escrita, que inevitablemente introduce la subtitulación. Gracias a ello el traductor tiene más posibilidades de reflejar en la traducción, entre otras cosas, las marcas de oralidad presentes en el texto original.

\section{LAS CAUSAS EXPLICATIVAS DEL VOICE OVER}

El voice-over no es una práctica desconocida en Occidente, si bien es cierto que se suele emplear sobre todo en la traducción de documentales, informativos televisivos, programas para niños y publicidad. Según Franco (2001), en el caso de los documentales se opta por esta modalidad para crear un efecto de autenticidad, es decir, para que los espectadores tengan la sensación de que la traducción que se les ofrece reproduce con exactitud todo el contenido del texto original. En Polonia, con la excepción de la publicidad (en la que muchas veces se suele recurrir al doblaje), el voice-over se emplea en todos los ámbitos anteriores y además en la traducción de las obras de ficción, lo que le confiere su excepcionalidad. Los datos, en este sentido, resultan abrumadores. De acuerdo con Garcarz (2007), aproximada- 
mente el 95\% de las traducciones para televisión se ofrece en su versión voice-over y ante ellos habría que preguntarse por las razones que explican tal preponderancia.

Suele afirmarse, un tanto injustamente, que el voice-over goza de popularidad en los países "with high illiteracy rates" (Grigaravičiūte y Gottlieb 1999: 42). Si esta afirmación fue cierta alguna vez, no lo es de modo alguno en la actualidad, ni tan siquiera lo era cuando los referidos autores firmaron su trabajo. Basta con consultar los informes de organismos internacionales, como UNESCO (2014) para comprobar que las tasas de analfabetismo en Polonia se sitúan en el mismo nivel que el resto de naciones europeas. Asimismo, el argumento del analfabetismo podría utilizarse también con respecto a los países en los que ha triunfado el doblaje, aunque muchos autores parecen no atender a ese matiz. Por otro lado, muchos trabajos dedicados al tema suelen pasar por alto que en Polonia el voice-over se da solo para las traducciones televisivas, ya que en cuanto a la traducción cinematográfica se le considera un país subtitulador (Comisión Europea 2011). Evidencia complementaria, si se quiere, del vínculo infundado entre la práctica del voice-over y altas tasas de analfabetismo.

Otro argumento, más acertado que el anterior, que ha sido reiteradamente evocado como origen del voice-over, son sus bajos costes de producción. A principios de la década de los 90, Marek Gajewski, un «lector» profesional (citado por Glaser 1991), justificaba la popularidad del voice-over con falta de recursos económicos por parte de los espectadores polacos para comprarse unas buenas gafas para leer los subtítulos, argumento este que hoy en día no puede sino sonar a broma. No hay duda, no obstante, que el voice-over es una modalidad más barata que el doblaje, ya que el número de profesionales involucrados es mucho menor: un traductor, un corrector (si lo hay), un «lector» y un técnico de sonido. Determinar sin embargo con exactitud la diferencia de costes entre una modalidad y otra resulta por lo menos complejo, ya que todo depende del tipo de obra, su duración, el país de procedencia, la lengua original, las propias tarifas y circunstancias de los profesionales, etc.

Un tercer argumento, vinculado con el anterior, se refiere a la rapidez de producción. Aunque Garcarz (2007) subrayaba que el voice-over era el más barato y rápido de todas las modalidades, la subtitulación incluida, los datos que maneja son de hace casi diez años y parece lógico pensar que con el avance tecnológico de la última década las cosas han cambiado sustancialmente, y que actualmente, en el caso en que tanto la traducción como el pautaje corran a cargo de un mismo profesional, la subtitulación es la alternativa más rápida y barata. De esta manera, el voice-over se situaría entre el doblaje y la subtitulación en lo que se refiere al coste y tiempo de producción.

Todos esos argumentos objetivos llevaron a dos grandes cadenas de televisión a intentar introducir una modalidad de traducción audiovisual distinta al voice-over. Primero, en los años 90 la televisión polaca, TVP, y Canal+ optaron por introducir en su programación un mayor porcentaje de películas dobladas. En el año 2001 abandonaron sin embargo este intento regresando a las versiones voice-over (Woźniak 2008). Cabe decir sin embargo que algunas obras dobladas han tenido una gran repercusión en Polonia. Este es el caso de la traducción de Shrek, realizada por Bartosz Wierzbięta, la cual marcó un antes y un después en la historia de la traducción audiovisual en Polonia. Se optó por una domesticación del texto, y algunas partes de la traducción de la película han entrado a formar parte del habla cotidiana de los espectadores polacos. Esa práctica se extendió a otras películas animadas y de momento se limita solo a dicho género. 
Un par de años después de los intentos de TVP y Canal+, BBC Prime se propuso convencer a la audiencia televisiva polaca de las bondades de la subtitulación, aunque los resultados fueron los mismos que en el caso anterior. En el año 2008 Polonia resultó ser el primer país en el que dicho canal dejó de emitir, lo que a su vez permitió la introducción de otros canales de BBC Global Channels, pero con la modalidad voice-over.

Todo esto refuerza la idea de que cualquier esfuerzo analítico que pretenda comprender la realidad de la persistencia del voice-over en las televisiones polacas no puede atender solo a las razones de carácter objetivo esgrimidas anteriormente, sino también debe dar cuenta de otras muchas razones de carácter subjetivo, ya que estas parecen constituir una variable de gran capacidad explicativa Más allá pues de las discusiones académicas en las que, con razón, se deslizan argumentos normativos, ningún trabajo que pretenda un análisis exhaustivo sobre el voice-over en Polonia puede menospreciar aspectos de índole mucho más pragmática, como lo es el simple hecho que los espectadores tienen unos esquemas de preferencias muy marcados, cuya inercia es muy difícil de modificar. En este sentido, varias encuestas llevadas a cabo para diferentes cadenas de la televisión polaca no dejan lugar a dudas sobre esas preferencias: el público televisivo polaco es partidario del voice-over. Por citar solo algunos ejemplos, según los sondeos realizados en el año 2002 por Instytut Badań Rynku i Opinii Publicznej SMG KRC (citados por: Bogucki 2004)³, entre las tres modalidades de la traducción audiovisual el 50,2\% de los encuestados dijo preferir el voice-over, el 43,3\% optó por el doblaje y solo el $8,1 \%$ por los subtítulos. Este patrón se confirmó parcialmente en los resultados del año 2005 en las encuestas llevadas a cargo para la televisión pública TVP (citadas por: Garcarz 2007): el 45\% de los encuestados declaró que su modalidad preferida era el voice-over, el $46 \%$ optó por el doblaje, mientras que solo el $4 \%$ los subtítulos en polaco y un anecdótico $1 \%$ dijo preferir la subtitulación en inglés. Por último, los sondeos realizados para la cadena de televisión BBC Prime (citados por: Subbotko 2008) revelan el mismo esquema de preferencias: mientras el $52 \%$ de los encuestados dice preferir el voice-over, solo el $4,2 \%$ se pronuncia más partidario de los subtítulos.

La costumbre y la pragmática parecen revelarse, pues, como sólidos argumentos para explicar la persistencia del voice-over en la traducción de la ficción televisiva en Polonia. Factores estos que incluso pueden considerarse caras de una misma moneda. La televisión polaca durante varias décadas ha ofrecido las películas en la versión voice-over por lo que los espectadores se han acostumbrado a esta modalidad, y no es de extrañar que en el momento en el que les ha sido planteado un posible cambio, hayan optado por aquella que les resulta más familiar. Tanto es así que, muy probablemente, las cadenas que pretendan invertir ese esquema de preferencias en los espectadores televisivos polacos, se arriesgan simplemente a una caída de sus cuotas de audiencia. A falta de estudios empíricos que permitan su corroboración, el argumento pragmático en relación a las preferencias del público parece emerger como una importante variable explicativa que, además, podría extenderse al análisis de la situación de cualquier otra de las modalidades de traducción. Ello, por ejemplo, permitiría ayudar a explicar la persistencia del doblaje en ciertos países.

Además de la familiaridad con el voice-over, la aversión a la subtitulación del público polaco parece estar causada también por la propia naturaleza de la lengua polaca. La profe-

3 Ante la imposibilidad de acceder a las fuentes primarias, probablemente debido al carácter comercial de las mismas, en este trabajo se ha optado por recurrir a fuentes secundarias, tales como Bogucki (2004), Garcarz (2007), o Subbotko (2008). 
sora Korcz (citado por: Subbotko 2008) sostiene que la lengua polaca, en comparación con la inglesa, está mucho más cargada de elementos de puro contenido gramatical (como los casos) y que el orden de palabras en la frase es, en su caso, mucho más flexible. Ello llevaría a los espectadores polacos a tener que procesar más información, no permitiendo tampoco una lectura más bien global, que sí es facilitada en cambio por la lengua inglesa. Según las palabras de Korcz, incluso los nativos chinos leen más rápido el chino que los nativos polacos el polaco.

Por último, es importante remarcar que la llegada de la televisión digital está permitiendo la convivencia de distintas modalidades, de tal manera que el espectador puede optar entre todas ellas, de acuerdo con sus propias preferencias. Stysiak (2015), afirma, sin embargo, que la opción de cambiar la versión voice-over por los subtítulos no siempre está disponible y admite que gran parte del público televisivo no es consciente de su existencia, ya que, de hecho, no existe todavía ninguna norma que regule esa cuestión y la decisión final depende de las propias cadenas televisivas. Así, uno de los canales privados, TVN, desde 2011 emite las películas tanto en la versión voice-over como en la versión original y con los subtítulos cerrados. E, incluso, el ente público de televisión, TVP, ofrece esa posibilidad de cambio de modalidad, emitiendo más de la mitad de las películas con ambas opciones (Stysiak 2015).

\section{CONCLUSIONES}

A pesar de la mala fama que tiene entre los investigadores del campo de la traducción audiovisual, las encuestas de opinión no dejan lugar a dudas: el público polaco prefiere el voice-over en lo que refiere a las traducciones de obras de ficción para la televisión. Ello hace, como se ha argumentado a lo largo de esta contribución, que la popularidad del voice-over no puede ser analizada en relación a unos factores objetivos y sugiere la incorporación de factores ligados a la pragmática de la traducción. En este sentido, el argumento más importante para explicar la persistencia del voice-over en la traducción de ficción televisiva en Polonia es la estructura de preferencias del público, fruto de la propia evolución histórica y social del país. De hecho, los intentos fallidos de las grandes cadenas de televisión para introducir otras modalidades de traducción audiovisual constituyen la prueba más evidente del arraigo de esas preferencias y de la necesidad de esa pragmática en el estudio de los fenómenos ligados a la traducción audiovisual.

Podría decirse entonces que las discusiones académicas que se limitan a las deliberaciones puramente estéticas y normativas parecen olvidar un factor más importante, el humano. En la televisión polaca reina el voice-over porque así lo prefieren los espectadores polacos. Es de esperar que con la televisión digital el público tenga un creciente acceso a distintas modalidades de traducción de una misma obra, pero cabría preguntarse a la vez si el rápido cambio tecnológico será suficiente para modificar determinados esquemas de preferencia, fruto de evolución social de las últimas décadas.

\section{BIBLIOGRAFÍA}

BARZDEVICS, Ivars, «Un recorrido por la voz superpuesta», en Juan José Martínez Sierra (coord.), Reflexiones sobre la traducción audiovisual. Tres espectros, tres momentos, Valencia, PUV Universidad Valencia, 2012, 57-69. 
BOGUCKI, Łukasz, «Relewancja jako ograniczenie w procesie tworzenia napisów», The Journal of Specialised Translation, 1, 2004, 69-84.

CHAUME, Frederic, Audiovisual Tranlation: Dubbing, Manchester, St. Jerome Publishing, 2012.

COMISIÓN EUROPEA, Study on the use of Subtitling - The potencial of subtitling to encourage foreign language learning and improve the mastery of foreign languages, Bruselas, 2011, http://eacea.ec.europa.eu/llp/studies/study_on_the_use_of_subtitling_en.php, última visita: 13-04-2015.

DELABASTITA, Dirk, «Translation and mass-communication: film and T.V. translation as evidence of cultural dynamics», Babel, 35(4), 1989, 193-218.

DOANE, Mary Ann, "The Voice in the Cinema: The Articulation of Body and Space», en Elisabeth Weis and John Belton (eds.), Film Sound: Theory and Practice, New York, Columbia $U \mathrm{P}, 1985$.

ESPASA, Eva, «Myths about documentary translation», en Orero Pilar (ed.), Topics in Audiovisual Translation, Amsterdam/Philadelphia, John Benjamins Publishing Company, 183-197.

FRANCO, Eliana, «Voiced-over television documentaries. Terminological and conceptual issues for their research», Target, 13 (2), 2001, 289-304.

FRANCO, Eliana, MATAMALA, Anna y ORERO, Pilar, Voice-over translation: an overview, Bern, Peter Lang, 2010.

GARCARZ, Michał, Przekład slangu w filmie. Telewizyjne przekłady filmów amerykańskich na język polski, Kraków, Tertium, 2007.

GLASER, Gabrielle, "Why Marilyn Monroe is a Polish Baritone», The New York Times, 2402-1991, http://www.nytimes.com/1991/02/24/movies/film-why-marilyn-monroe-is-apolish-baritone.html, última visita: 13-04-2015.

GRIGARAVIČIŪTE, lewa y GOTTLIEB, Henrik, "Danish voices, Lithuanian voice-over. The mechanics of non-synchronous translation», Perspectives: Studies in Translatology, 7(1), 1999, 41-80.

HENDRYKOWSKI, Marek, Słowo w filmie, Warszawa, Państwowe Wydawnictwo Naukowe, 1982.

HENDRYKOWSKI, Marek, «Z problemów przekładu filmowego», en Edward Balcerzan (ed.), Wielojęzyczność literatury i problemy przekładu artystycznego, Wrocław, Polska Akademia Nauk, 1984.

HURTADO ALBIR, Amparo, Traducción y traductología. Introducción a la Traductología, Madrid, Cátedra, 2013.

PISARSKA, Alicja y TOMASZKIEWICZ, Teresa, Współczesne tendencje przekładoznawcze, Poznań, Wydawnictwo Naukowe UAM, 1996.

STYSIAK, Martin, «Telewizje w Polsce nie pokazują filmóww oryginalnej ścieżce dźwiękowej. Dlaczego?», Gazeta Wyborcza, 07-02-2015, http://wyborcza.biz/biznes/1,100896,17371355, Telewizje_w_Polsce_nie_pokazuja_filmow_w_oryginalnej.html?biznes=local\#BoxBizlmg, última visita: 13-04-2015.

SUBBOTKO, Donnata, «Kapitulacja BBC Primer», Gazeta Wyborcza, fecha: 11-01-2008, http:// wyborcza.pl/1,75475,4827095.html, última visita: 13-04-2015.

SZARKOWSKA, Agnieszka, "The audiovisual landscape in Poland at the dawn of the $21^{\text {ST }}$ century», en Angelica Goldstein y Biljana Golubović AA. W., Foreign Language Movies - Dubbing vs. Subtitling, Hamburg, Verlag Dr. Kovač, 2009. 
TOMASZKIEWICZ, Teresa, Przekład audiowizualny, Warszawa, Wydanictwo Naukowe PWN, 2006.

UNESCO, Adult and Youth Literacy, París, 2014, documento disponible online: http://www. uis.unesco.org/Library/Documents/fs29-adult-youth-literacy-2014-en.pdf, última visita: 13-04-2015.

WOŹNIAK, Monika, «Jak rozmawiać z kosmitami? Kilka uwag o tłumaczeniu lektorkim telewizyjnych filmów fantastyczno-naukowych (na przykładzie Star Trek)»Przekładaniec, 20(1), 2008, 50-89.

ZABALBEASCOA, Patrick, «El texto audiovisual: factores de semióticos y traducción», en John D. Sanderson (ed.), ¡Doble o nada! Actas de las I y II Jornadas de doblaje y subtitulación de la Universidad de Alicante, Alicante, Universidad de Alicante, 2001, 113-126.

\section{Obras audiovisuales:}

JECZEŃ, Michał, Zawód lektor, Alina Gaworska (prod.), Polonia, 2006.

Quaderns, 10 (2015), pp. 63-72 